\title{
Representações sociais sobre direitos e violência na área da deficiência
}

\author{
Social representations of rights and violence in the disability field
}

Fátima Gonçalves Cavalcante ${ }^{1}$

M aria Cecília de Souza M inayo ${ }^{1}$

${ }^{1}$ Centro Latino-Americano deEstudos de Violência e

Saúde Jorge Carelli, Escola Nacional deSaúdePública, Fiocruz. Av. Brasil 4036/ 700, M anguinhos. 21040361 Rio deJaneiro RJ. fatimagold7x7@yahoo.com.br
Abstract This article presents the analysis of relations and social representations from professionals, leaderships and families about the rights of children and teenagers with disability and violence against them. It is part of a major study which occurred in three Rio de Janeiro's institutions for that population. Its merit is to show up the logic of institutions, professionals and families involved in the special care as an essential part of quality's attention. This study is based on narratives of different actors about the specificity of their work and in group's discussion of difficulty faced in the care they offer, in the interaction among them and with society, and in the view they project into the themes rights of disabled person and the manifestations of violence against them. We took into account a theoretical revision up-to-date related to different visions and perspectives about people with disability, their support and the carethey need. We concluded for the need of giving more attention not only for the disabled people, but mainly to families and professionals which take care of them, in order to empower people and programs. Key words Rights, Violence, Disability, Family, Professional, Social representation
Resumo Este artigo apresenta uma análise sobre relações erepresentações sociais de profissionais, gestores e familiares a respeito de direitos de crianças e adolescentes com deficiência e de violências cometidas contra eles. É parte deum estudo amplo ocorrido em três instituições do Rio de Janeiro que prestam serviços a esses jovens. Seu principal mérito é trazer a público a lógica das institui ções, dos profissionaise dos familiares envolvidos nos cuidados como parte essencial da qualidade da aten ção. Esse estudo sebaseou em narrativas dos diversos atores sobre as especificidades do seu trabalho e em grupos de discussão sobreas dificuldades queenfrentam nos cuidadosque oferecem, na interação entre si e com a sociedade e na visão queprojetam sobre os temas di rei tos da pessoa com deficiência emanifestações de violências que sofrem. Levamos em conta um referencial teórico atualizado quetrata das diferentes visões eperspectivas sobrea pessoa com deficiência e do apoio ecuidado de que necessita. Concluímos pela necessidade de dar maior atenção não apenas ao deficiente, mas principalmenteà família e aos profissionais quecuidam dele, numa visão de fortalecimento das pessoase dos programas.

Palavras-chave Direitos, Violência, Deficiência, Família, Profissional, Representações sociais 
Introdução

Este artigo sobre representações sociais a respeito dos direitos e da violência na área da deficiência é resultado de uma análise feita a partir de uma investigação qualitativa anteriormente descrita por Cavalcante et al. ${ }^{1}$ em três instituições do Rio de Janeiro, com apoio do Conselho Nacional de Desenvolvimento Científico eTecnológico/M inistério da Saúde/ Departamento de Ciência e Tecnologia (CN Pq/M S/DECIT) e da Fundação de Amparo à Pesquisa do Estado do Rio de Janeiro (FAPERJ). 0 foco do estudo aqui apresentado traz facetas iné ditas da referida investigação, situando o cotidiano das instituições estudadas e o modo como profissionais, gestores e familiares lidam com a questão dos direitos e com as expressões de violências, a partir de uma análise de narrativas e da cultura institucional. As narrativas foram precedidas por cuidados metodológicos e técnicas grupais que favoreceram a abordagem do referido tema e se mostraram válidas, podendo ser replicadas em estudos semel hantes.

Estudar as representações sociais é buscar conhecer o modo como um grupo humano constrói um conjunto de saberes e expressa sua identidade, atribui sentido a uma diversidade de objetose, principalmente, constrói códigos culturaisquedefinem, em cada momento histórico, as regras de uma comunidade. N estetexto, mostramos como um conjunto de representações sobre deficiência, direitos e violência nos ajuda a compreender o comportamento das pessoas que transitam nesse universo, oferecendo um serviço que é indelevelmente marcado por seu modo de pensar, sentir e agir. Por isso, apresentamos descrições da realidade física, cognitiva, afetiva, social ecultural de forma objetiva e subjetiva, colocando-nos em contato com questões que merecem ser conhecidas.

O tema "direitos e violência" será apresentado, a seguir, em suas conexões com a infância mais amplamente e, mais especificamente, com a área da deficiência infanto-juvenil para, então, seguir com detalhamentos da pesquisa, análise e discussão dos dados e recomendações finais.

Direitos das crianças e adolescentes em geral e com deficiência

Os Direitos da Criança estão promulgados numa Convenção da ONU de $1989^{2}$, na Constituição Brasileira ${ }^{3}$ de 1988 no seu artigo 227 eno Estatuto da Criança e do Adolescente de $1990^{4}$. Todos esses documentos reportam aos princípios fundamentais estabelecidos na D eclaração Universal dos
Direitos Humanos ${ }^{5}$, que asseguram a universalidade dos direitos humanos e se aplicam a todo ser humano sem distinção; a responsabilidade de todos no sentido de proteger, cumprir e respeitar esses direitos, sua indivisibilidadeeinterdependência, devendo o Estado garanti-los por medidas legais. Por fim, a Declaração garante a participação de todos os seres humanos no processo de tomada de decisão sobre seus direitos.

Duas declarações sobre a questão da pessoa deficiente se destacaram na década de 1970: a Declaração dos Direitos do D eficiente M ental ${ }^{6}$ de 1971 e a Declaração dos Direitos das Pessoas D eficientes $^{7}$, de 1975. Esses documentos refletem um período histórico marcado pelo modelo médico da deficiência, circunscrito à reabilitação e à busca de maior integração social, quando a demanda de adaptação era esperada pelos deficientes, famílias einstituições.

$N$ as décadas que antecederam e sucederam a virada do século XXI, transformações paradigmáticas importantes ocorreram principal mentequanto à concepção do modelo social da deficiência. Essa mudança desafiou a sociedade, exigindo novas práticas, sobretudo quanto à inclusão da pessoa deficiente nos contextos de crescimento e de desenvolvimento. 0 ano de 2003 foi considerado 0 Ano Europeu das Pessoas com Deficiência, tendo como marco o Congresso Europeu de Deficiência, culminando com a Declaração de M adri ${ }^{8}$ em 2004. Nesse evento, a deficiência foi tomada como uma questão de direitos humanos a serem assegurados, conforme a idéia de que a sociedade deve se modificar para favorecer a inclusão (educação inclusiva, acesso a novas tecnologias, saúde e serviços sociais, desporto e atividades de lazer, produtos, bens e serviços de defesa dos consumidores); incentivo a políticas que respeitem a heterogeneidade da deficiência ( pessoas com necessidades em níveis diferenciados e suas famílias, o que requer ações específicas); afirmação de queo direito à nãodiscriminação deve ser completado pelo direito a receber apoio e assistência.

No Brasil, pesquisas realizadas por Ferreira ${ }^{9} \mathrm{e}$ Cavalcante et al. ${ }^{10}$ sobre direitos da criança e do adolescente com deficiência constataram que quase a totalidade de pessoas entrevistadas não teve acesso aos documentos anteriormente referidos e desconhecea legislação brasileira pertinente. A falta de informação sobre possibilidades de sucesso de crianças e joven s com deficiência quando cumprem atividades da vida regular também contribui para perpetuar o mito de que são incapazes de aprender. 
Violência contra crianças e adolescentes em geral e com deficiência

Um relatório da Organização das Nações Unidas ${ }^{11}$ sobre direitos humanos e violência contra criança, considerado o mais recente e consistente estudo global focado na infância, concluiu que a violência contra esse grupo social ocorre em todos os países do mundo, atravessa todo tipo de cultura, educação, classe, renda e origem étnica. Contraditoriamente, essetipo deviolência ésocialmente aprovado e, com freqüência, é autorizado pelo Estado. Vejamos alguns dados.

Deacordo com estudos internacionais ${ }^{11-13}$, pelo menos 106 países não proíbem o uso de punição corporal nas escolas, 147 países não o proíbem em centros alternativos de cuidado e apenas dezesseis países proíbem a punição física em casa. Além disso, cerca de 53.000 crianças morreram por homicídio no mundo e 150 milhões de meninas e $73 \mathrm{mi}$ Ihões de meninos abaixo de 18 anos sofreram abuso sexual em 2002; entre 100 e 140 milhões de meninas e mulheres sofreram mutilações e corte dos genitais femininos em 200511,14,15. Por fim, estudos revelam que mais de $80 \%$ das crianças em geral sofrem punição física em casa, sendo um terço destas consideradas severas. E 218 milhões de crianças estiveram envolvidas em trabalho, das quais 126 milhões em trabalho forçado em 2004 ${ }^{11,16}$.

Quanto à prevalência por tipo de violência, observamos que crianças pequenas são mais vítimas de violência física; meninas a partir da puberdade, deviolência sexual, negligência e prostituição forçada; e meninos a partir da puberdade também são alvo de violência física. Estima-se que 133 a 275 miIhões de crianças sofrem violência doméstica anualmente, seja pela exposição à briga entre os pais, seja pela interação abusiva entreo adul to ea criança ${ }^{11,17}$. Estudos em menor escala revelam outros grupos vulneráveis que geralmente nem são nomeados em pesquisas e documentos enem entram em estatísticas: crianças com deficiência, grupos de minorias étnicas, meninos derua, meninosemeninas em conflito com a lei, refugiados, entre outros ${ }^{11}$.

Embora existam poucas informações sobre a violência contra crianças e adolescentes com deficiência, é possível traçar um panorama sobre o problema.

Estudo do Banco Mundial revelou que meio bilhão de pessoas com deficiência são as mais pobres, entre os pobres ${ }^{18}$. Segundo a Organização M undial de Saúde, existem cerca de 200 milhões de crianças e adolescentes com deficiência, com incapacidades físicas, sensoriais, como cegueira e surdez, déficits intelectuais e transtornos mentais em todo o mundo. Cerca de 10\% da população jovem mundial até 19 anos nasceram com uma deficiência ou a adquiriram posteriormente. No entanto, conforme dados recentes da United Nations Children's Fund (UNICEF), apenas 3\% das crianças com deficiência estão na escola e o maior contingente de adultos com deficiência está excluído do mercado de trabalho ${ }^{19,20}$.

Alguns estudos epidemiológicos indicam maior risco de exposição à violência devido ao estigma, a crenças negativas, à falta de clareza sobre as incapacidades e desvantagens e à falta de suporte social ${ }^{21-23}$. Estima-se que a violência contra crianças com deficiência ocorra numa taxa anual 1,7 vezes maior do que entre crianças em geral ${ }^{24}$. Esse risco aumentado não está associado à deficiência em si, ou ao estressepsi cológico que envolve o cuidado de uma pessoa com deficiência, mas aos fatores sociais, culturais eeconômicos que criam um imaginário social negativo sobre a questão. A violência e deficiência costumam estar associadas a um ou mais fatores de risco, como pobreza, moradia precária ou falta de moradia, isolamento social, marginalização, minoria étnica, família monoparental, mãe adolescente, drogadição, alcoolismo, enfermidade física incapacitante, enfermidade mental, o que pode vir a configurar um perfil de "famílias multiproblemáticas" 25.

A prevenção da violência naárea de deficiência infanto-juvenil deve, portanto, levar em conta três problemas que se sinergizam: (1) criança com deficiência e sua vulnerabilidade diante da violência; (2) criança ou adolescente com deficiência na família e sua vulnerabilidade diante da pobreza; (3) interação de múltiplas vulnerabilidades em face da associação entre deficiência, violência e pobreza, conforme descrito por Cavalcante e Goldson ${ }^{26}$.

\section{M aterial e método}

Descrevemos apenas o detal hamento da parte do estudo de Cavalcante et al. ${ }^{1}$ no que se refere aos grupos de discussão (GD) com 216 profissionais; aos grupos de reflexão (GR) com 99 familiares; às entrevistas semi-estruturadas com dez gestores eà contextualização das instituições. 0 ol har sobreos dados colhidos no trabal ho de campo tem o intuito de oferecer bases para uma análise de representações dos diversos atores e de suas interações, sobre os doistemas, direitos e violência no contexto da deficiência; assim como auxiliar na análiseda cultura organizacional e das estratégias sociais mobilizadas para enfrentar obstáculos e buscar soluções frente aos temas estudados. 
Asrepresentações sociais segundo Guareschi ${ }^{27}$ são "teorias" sobre saberes populares edo sen so comum, elaboradas e partilhadas coletivamente com a finalidade deconstruir e interpretar o real. Para M oscovi$\mathrm{Ci}^{28}$, elas são os equivalentes aos mitos e sistemas de crença das sociedades tradicionais e versão contemporânea do senso comum. E Jodelet ${ }^{29}$ as conceitua como uma forma de conhecimento, socialmente elaborada e partilhada, dentro de uma visão prática e concorrendo para a construção de uma realidade comum. Uma das características fundamentais das representações sociaiséqueelas constituem uma síntese entre cognição, afeto e ação. É nesse sentido que aqui serão tratadas ${ }^{30}$, para compreensão dos discursos e das narrativas sobre as quais trabalhamos.

0 trabalho de campo foi realizado por meio de grupos de discussão, grupos de reflexão e entrevistas semi-estruturadas.

Utilizamos o grupo de discussão como uma estratégia de sensibilização de profissionais sobre violência e direitos, visando a: (a) aproximar pesquisadores e funcionários, antecipar problemas e estabelecer negociação de fronteiras; (b) trabalhar expectativas, receios e mal-entendidos, e compreensão do significado da pesquisa; (c) introduzir a discussão sobre direitos humanos sob forma de palestra (GD-DH), tomando como base um guia sobredireitos $s^{9}$ eviolência doméstica einstitucional (GD-VDI), sob a forma de estudo de caso; (d) distribuir materiaisinstrucionaisaosfuncionáriospara suporte teórico dos temas pesquisados.

Os grupos de reflexão com famílias foram realizados nas instituições de reabilitação e social. A pesquisa foi apresentada através de uma palestra baseada no guia sobre direitos ${ }^{9}$, seguida de dois encontros, focando os temas direitos (GR-D) e violência (GR-V), a partir de roteiros semi-estruturados. 0 grupo foi convidado a fazer associação livre, conceito da psicanálise que propõe o livre pensar das pessoas, processo que permite verificar a evolução do tema, as angústias que ele produz e as soluções que o coletivo vai encontrando para elaborálas e para dar sentido às experiências narradas.

As entrevistas semi-estruturadas com os gestores se realizaram ao final do trabalho de campo. Elas foram cruciais para a compreensão da dinâmica, da cultura e das práticas institucionais, bem como da visão dos gestores sobre as políticas públicas articuladas às práticas.

Nos grupos com os profissionais, os pesquisadores foram inicialmente recebidos com reações que variaram entre cautela e preocupação, sentimento de invasão e receio de se ver exposto a constrangimentos, hostilidade e ressentimento. Alguns funcionários disseram que a pesquisa seria bem- vinda, pois traria uma oportunidade de troca e informação e serviria como capacitação para técnicos, profissionais e famílias. O utros ficaram receosos diante da possível exposição de seu trabaIho, com medo de serem responsabilizados por situações que não conseguem denunciar. Um dos grupos questionou sobre os efeitos práticos deuma investigação: "a teoria pode ser bonita, porém a prática é que são elas". E alguns profissionais argumentaram: "fala-se muito em direitos humanos, porém em deveres fala-se pouco".

Sobretudo na instituição que atua próxima a uma favela onde realmente todos vivem num ambiente social de elevado risco, inicialmente houve uma crítica acirrada à figura do pesquisador como um intruso no ambiente. Essa postura foi confrontada com a superioridade da prática que dá aos profissionais o domínio de seus objetos de trabalho. Para alguns, materializava-se, naquele momento, um jogo de forças em que expressões de descrença em relações a pesquisas e a abordagens teóricas estavam aliadas a manifestações implícitas e explícitas de insatisfações tanto com a instituição quanto com as dificuldades do cotidiano de trabalho. Esse jogo demarcou uma relutância a cerca do que se poderia ou não falar sobre a violência vivenciada no dia-a-dia da assistência a crianças, adolescentes e jovens com deficiência e suas famílias, bem como sobre a violência crescentenas comunidades pobres do Rio de Janeiro.

A análise do material qualitativo foi realizada dando ênfase às estruturas de relevâncias dos sujeitos e à lógica interna do pensamento, dos sentimentos e das ações dos grupos e das instituições ${ }^{30}$.

\section{Resultadosediscussão \\ Perfil das instituições}

Três instituições foram estudadas:

(1) uma do terceiro setor e de pequeno porte, caracterizada pel o modelo de reabilitação quetransita entre a saúde e a educação, trabal hando reorganização psicossocial e integração social da pessoa com deficiência, especialmente com deficiência múltipla; (2) umainstituição federal demédio porte, caracterizada pelo modelo médico, voltada para atenção secundária e terciária ligada ao SUS, com hospital ecentro de referência para doenças dealta complexidade. Essa organização apresenta tecnologia de ponta para assistir com qualidade e de modo humanizado pessoas com doenças materno-infantis crônicas, visando à desospitalização através de assistência domiciliar; 
(3) uma instituição municipal degrandeporte, caracterizada pelo modelo social, com unidades e programas centralizados e descentralizados, atentos à realidade local e comunitária, comprometida com a promoção social, a inclusão, a reabilitação e a atenção aos riscos sociais. Essa organização vaIoriza a atuação em rede e a intersetorialidade

Cada modelo descrito, ora fortalecendo a pessoa com deficiência e sua família, ora prolongando a vida através de tecnologia de ponta, ora promovendo a inclusão e atuando na promoção social e no apoio residencial em comunidade, tem importância inegável para a assistência global da pessoa com deficiência, cada qual com sua especificidade.

Análise das narrativas dos profissionais, gestores e famílias sobre violência e direitos

As diferenças entre as instituições e os seus respectivos modelos de atendimento refletiram-se em modos distintos de se apropriar do tema "direitose violência". Nas instituições ligadas ao modelo mé dico e de reabilitação, o tema dos direitos ganhou maior visibilidade e na instituição de atuação no âmbito social, o tema violência se destacou com veemência, especialmente nas narrativas dos profissionais e gestores. Entre as famílias, predominaram demandas acerca dos direitos e vivências sobre o dia-a-dia de cuidados ao filho com deficiência.

\section{Sobre as várias representações de violência}

Iniciamos pela análise de diferentes maneiras de ver, sentir e descrever a violência e formas de reagir em relação a ela. $\mathrm{Na}$ instituição que funciona num ambiente de forte risco social, a violência aparece como uma noção difusa que afeta o modo como os atores interpretaram a própria pesquisa. Os profissionais se percebem impactados por ela, no modo como interagem com locais e situações do cotidiano e até na forma como abordam a criança com deficiência ea sua família. A violência foi descrita como algo difícil, perigoso e ameaçador, pois quando enfrentada provoca reações indesejadas, afetando a relação do profissional e da instituição com a família ea comunidade. Os tipos mais freqüentemente citados foram a violência social local, a violência intrafamiliar, as negligências do Estado e a violência contra os profissionais. Nos relatos, os vários tipos desse fenômeno compareceram fazendo sinergia. Sobressaem a violência social difusa e os maus tratos no âmbito familiar.

Em todas as três instituições pesquisadas, mas principalmente na que está próxima a uma favela onde há forte presença de grupos de traficante em permanente confronto com a polícia, os profissionais foram diretos ao dizer que a violência "causa problemas para o profissional que está atendendo, para a família dentro da comunidade onde reside, para o deficiente dentro da família e para todos os envolvidos". Desta forma, esse fenômeno foi considerado um "tema-problema" que causa transtornos, mesmo quando apenas falamos dele. Alguns profissionais, nos grupos de discussão, indagaram se a pesquisa não iria ameaçar seu vínculo com as famílias, pois com certeza Ihes seria exigido um posicionamento frente a casos conhecidos de maus tratos aos deficientes. Afinal, interrogou um profissional: "que família iria querer dar sua cara a tapa?"

Ficou claro para nós que os problemas mais agudos são de maus tratos e abusos no âmbito intrafamiliar. E frente a eles, os profissionais consideram risco pessoal o fato de detectar e notificar casos de dinâmica de violência, criando-se assim uma tendência à omissão, justificada pela preservação de sua atuação técnica e pelo respeito ao mundo privado.

Por isso, uma pesquisa como essa, que pautou o assunto e mostrou a sua relevância para o crescimento e o desenvolvimento das crianças e jovens deficientes, foi vista como ameaçadora das rotinas institucionais. Essa sensação por parte dos profissionais foi adensada pela nossa proposta de discussão de um guia de direitos: "Para que serve esse tipo de guia? Para encher prateleiras? 0 que esta pesquisa trará como contribuição efetiva? M ais um guia como esse?"

Segundo um dos gestores da instituição que funciona próxima a uma favela, a entrada dos pesquisadores foi percebida como uma interferência "num ambiente já mexido", ou seja, já socialmente conturbado e, daí, a reação negativa. O utro gestor nos confidenciou que o imaginário em torno de nosso trabalho era a de que a pesquisa iria abordar um tema extremamente difícil de forma inconseqüente. Disseele: o outdoor do primeiro momento do estudo era: Vamos ter vocês [os pesquisadores] conosco ou vocês vão incendiar? Acho que essa foi a grande questão: vocês vão incendiar e cair fora. $\mathrm{E}$ aí? 0 que faremos como isso? A imagem da pesquisa como uma intervenção explosiva a colocou na ordem de uma potente violência simbólica cometida por nós pesquisadores: faríamos um estrago, acenderíamos conteúdos difíceis e controlados pelos profissionais e pela instituição e, ao final, Ihes deixaríamos a responsabilidade de lidar com as conseqüências e efeitos. Ostécnicos nem queriam tocar no assunto violência, considerando que já tinham problemas demais com a questão da deficiência. 
Outro gestor comentou que a relutância dos profissionais em discutir a violência se deveao fato de que seu trabalho nas comunidades está fundamentado numa palavra-chave, "credibilidade": há muito respeito das famílias que abrem suas casas para esses profissionais entrarem eabrem suas vidas para eles conhecerem. Em relação à existência de violência intrafamiliar, essa frase revela com clareza o receio e o impasse que atravessa a prática institucional. Existe uma estratégia de entrada no mundo da família que se afigura como pacto de silêncio sobre sua vida privada.

Toda essa reação nos pareceu ter lógica, uma lógica própria desse grupo. No entanto, não podemos justificá-la, pois a pretensa inviolabilidade do espaço familiar caiu por terra com o ECA ${ }^{10}$, segundo o qual a criança, sujeito de direitos e de proteção, deixa de ser propriedade dos pais. Assim, o princípio da inviolabilidade ou do anonimato da vida privada não podeser colocado acima do princípio da proteção à criança e ao adolescente.

Os impasses para lidar com o tema da violência surgiram claramente nas perguntas que os grupos formularam para expressar sua perplexidade: Como fazer com os trabal hos que precisam "ter vista grossa" sobre a violência para que possam ser realizados? Como mexer em áreas de extremo risco como várias das comunidades em quetrabalhamos? Como será possível levantar essa questão num lugar onde se respira violência enão saber se vocêpoderá sair ileso e continuar exercendo o seu trabalho? Essas perguntas revelam as dificuldades reais de atuação de uma instituição que cuida de problemas tão delicados como é o caso das deficiências, num ambientesocial hostil. A intensidade da ameaça vivenciada no nível psicossocial pelos profissionais, que se expressou nas críticas acirradas à pesquisa, reflete. como numa imagem projetada em espel ho, a intensidade do problema e o modo como sua confrontação faz sofrer aqueles que testemunham cotidianamente as várias faces da violência. Ou seja, a pesquisa sobre violência ameaçou profissionais e atividades na mesma intensidade em queel es esuas práticas estão, de fato, expostos a esse problema em suas várias formas. Nesse cenário, entendemos que o profissional também precisa de formação, decuidados, de atenção e de acompanhamento, como é referido no pedido de socorro de um deles: 0 que fazer com aquele profissional que sofre violência também?

A eloqüência dos impasses para lidar com a violência local esocial, como foi apresentada anteriormente, levou o coordenador da pesquisa a dar o seguinte retorno aos profissionais: 0 Programa está parecendo também uma "vítima de violência" e vocês [as equi pes] estão tão ameaçadas, amedrontadas e imobilizadas pelo medo como as vítimas de violência costumam ficar. Será possível não se deixar imobilizar pelo medo e cuidar dos efeitos de uma violência que vocês testemunham em condição de impotência?

Além do tema da violência difusa e intrafamiliar - esta última mais insinuada que explicitada -, surgiram menções, em todos os grupos e entrevistas, a um tipo de violência institucional e estrutural que se configura como ausência ou a defasagem de programas suficientes e adequados para 0 atendimento das pessoas com deficiência. N esse caso também, os pesquisadores foram questionados e sua prática desval orizada, talvez pela consciência de que uma pesquisa não tem como dar respostas imediatas aos problemas que enfrentam: mexem, incomodam e depois abandonam. 0 que vamos fazer ao término da pesquisa, depois que se mexeu nesse assunto tão difícil, e quando os pesquisadores vão embora? Enfim, de que adianta levantar questões como essa, se as políticas públicas não vão nos dar retorno? N esse caso específico, os pesquisadores foram colocados pelos profissionais ao lado das autoridades públicas, como seres inoportunos que podem provocar efeitos deletérios, por não trazerem contribuições concretas e aplicáveis a seus trabal hos.

No mesmo sentido, mas num tom afirmativo, os gestores se manifestaram, desejando que a interven ção realizada pela pesquisa não ficasse restrita à academia: A política não existe fora do ambiente social. Eu acho que os pesqui sadores têm obrigação de estar falando, de estar denunciando, de estar tendo ações práticas. Porque senão, para que a descoberta? Quero dizer, a ciência tem que fazer a diferença no dia-a-dia da pessoa. É isso que eu espero: mais da ciência e dos pesquisadores.

Ao contrário do que alguns profissionais verbalizaram, dizendo que "muitas famílias não iriam querer dar sua cara a tapa", pais e, sobretudo, mães se interessaram em participar do grupo de reflexão e, ao perceber uma escuta solidária e compreensiva, fizeram depoimentos espontâneos sobre violência, no sentido de reconhecer o sofrimento psíquico implicado na vida junto com pessoas deficientes sem os meios necessários para crescer ese desenvolver.

\section{Representações sobre direitos}

Concepções sobre direitos apareceram nos três modelos institucionais, na fala dos profissionais, famílias e gestores, estando relacionadas, sobretudo, à qualidade da assistência às pessoas com deficiência. As áreas de educação, mercado de traba- 
Iho, saúde e rede hospitalar, transporte público e saneamento básico foram principalmente questionadas. As famílias apontaram, principalmente, a necessidade de se lhes oferecer mais informações sobre as leis que as protegem e sobre as instituições voltadas para sua assistência.

Nas representações sobre direitos, observamos, em primeiro lugar, uma descrença em relação à aplicação das leis: "as leis estão no papel, mas não funcionam". 0 amparo promovido pela existência de dispositivos legais se contrapõe ao desamparo vivenciado na prática pelos profissionais einstituições que, freqüentemente, além de cumprir sua função social, têm que se envolver na defesa daqueles que são atendidos. Alguns profissionais, no entanto, em suas falas, reconheceram algumas conquistas importantes como o Benefício de Prestação Continuada (BPC), a Bolsa Família e outros. M encionaram, no mesmo sentido, o Estatuto da Criança e do Adolescente, como uma das leis mais avançadas que pode ser acionada por eles.

Algumas questões mereceram atenção especial dos entrevistados. Dentre elas, destacamos a dificuldade de inserção e a permanência da criança e do adolescente com deficiência na escola. Muitos profissionais citaram que existem setores e programas que buscam atuar na autonomia do portador de deficiência, preparando-o para o trabaIho, quando isso é possível, mas faltam alternativas para sua inserção no mercado de trabalho. Foi também muito criticada pelos técnicos e gestores a precariedade da rede hospitalar e a falta de preparação dos profissionais da saúde para atender às pessoas com deficiência e seus familiares. E a maioria dos técnicos assinal ou a falta de informação e a ignorância quanto às leis promulgadas para proteger os deficientes e a falta de capacidade das famílias para buscar a garantia de seus direitos.

Já nos grupos com as famílias, o tema mais discutido foram as dificuldades para conviver e lidar com os filhos deficientes, principalmente quando Ihes faltam condições materiais e poder para oferecer-Ihes conforto eassistência. N um grupo majoritariamente composto por mães e muIheres, com a participação de al guns poucos paise irmãos, percebemos sentimentos de desamparo social e de insatisfação com os órgãos públicos, com os serviços de assistência em geral, com a falta de estrutura da rede básica de saúde e de educação, e com a precariedade dos serviços de transporte coletivo. 0 ponto mais relevante dessa sensação de desamparo convergiu para as dificuldades detransportar os filhos. M uitos familiares colocaram essa responsabilidade nas instituições que os atendem. Consideram fundamental queessas entidades pro- videnciem o deslocamento de seus filhos, especialmente dos cadeirantes.

Sobretudo as mães, em consenso, falaram da dificuldade em conciliar trabalho eresponsabilidades de cuidado eamparo aosfilhos com deficiência. Comentaram que, na maioria das vezes, vêem-se obrigadas a abandonar a carreira e o emprego, com conseqüente perda na renda familiar e queda do poder aquisitivo, justamente no momento em que a família mais precisaria de recursos. Um pai diz ter perdido o emprego em virtude do tempo extra de que precisou dispor para cuidar de um filho com deficiência. Todos os familiares se queixaram muito dos preconceitos e discriminações e, principalmente, da falta de alternativas oferecidas pelo Estado: N ós queremos muito pouco. Queremos uma escola que funcione, um hospital que funcionee saneamento básico. Isso é o mínimo. Por isso, consideram que precisam de muito mais apoio dos governos locais e das instituições, por meio de programas sociais que Ihes assegurem uma qualidade de vida melhor e maior flexibilidade da carga horária de trabalho, pontos considerados necessários para darem sustento e conforto a seus filhos.

Num dos grupos de reflexão, familiares chegaram a formular propostas a serem levadas ao governo. Uma delas é que fossem criados pólos de assistência social em diversos bairros e nesses fossem incluídos bancos de dados sobre leis, benefícios einstituições especializadas no atendimento à pessoa com deficiência. Outra, é que fosse elaborada "uma carteira de mãe de filho deficiente", documento que Ihes permitissem atendimento mais rápido em instituições e acesso ao transporte público: A mãe teria um documento, qualquer coisa que provasse que ela tem um filho especial, para ela poder chegar a certas coisas governamentais ou não governamentais eapresentar. U ma mãe que tem um filho especial, ela não dispõe de tempo de ir para fila de posto de saúde e pegar número. E tem essa burocracia no posto de saúde. Muitos familiares de fiIhos com deficiência consideram que as questões graves [as que aqui foram citadas por eles] estão sendo esquecidas! Sea gentequiser, tem queir à luta. Se a gente não for, não consegue nada mesmo.

\section{Consideraçõesfinais}

Em síntese, observamos que, na fala dos gestores, dos profissionais e dos familiares, violência e desrespeito aos direitos são temas interligados. É o que resume o depoimento de um gestor: À medida que toma conhecimento dos seus direitos, a pessoa com deficiência toma conhecimento de que não é só 
ela que tem uma deficiência e que não precisa ficar escondida em sua casa, pois a deficiência, necessariamente não vai limitá-la, por completo, ela pode abrir outros campos. A família esclarecida vai gerar a prevenção da violência. Se eu não sei os meus direitos, eu não sei que eu estou sendo violentada, eu não sei se estou sofrendo racismo, eu não sei se estou sofrendo discriminação. As coisas vão ocorrendo em cadeia, semprejuntas.

A visão articulada entre direitos e violência reforça a importância da difusão e da promoção dos dispositivos legais, em articulação com a oferta de formas de proteção e preven ção.

No que concerne ao tema da violência, pudemos observar uma representação quase totalizante em relação à vida social. Ressaltamos que ela é vista invadindo todos os meandros do trabalho social etécnico, dificultando seus resultados, imobilizando a ação institucional e de pessoas e criando medo e insegurança. 0 diagnóstico dessa situação, no entanto, nos induz a dizer que é preciso atuar nessas instituições para queo reconhecimento de que o problema existe seja acompanhado pela devida atuação.

Um dos resultados mais enfáticos da pesquisa foi a constatação do despreparo profissional einstitucional para abordar a violência, tema que adquire maior gravidade em áreas de intenso risco social. Silêncio, medo de retaliação e estigma são fatores fortemente associados à hesitação da denúncia, cuja evidência põeem risco a honra depessoas, famílias ou instituições e encoberta muitas formas de crueldade contra crianças, adolescentes ejovens com deficiência.

A aceitação social da violência é um dos fatores de reprodução desse mal e precisa ser superado, 0 que demanda mudança de cultura organizacional. Por isso é preciso investir nas equipes técnicas, pois os profissionais também estão expostos a suas manifestações, inclusivealguns podem ter sido vítimas na infância, ou o são até hoje, de abusos e maus tratos que precisam reconhecer, enfrentar e transformar.

Quanto aos jovens e crianças com deficiência, precisamos ter consciência de que a violência vivenciada ou testemunhada traz-Ihes um risco dobrado de traumatizações. Portanto, é fundamental que os profissionais atuem também em relação aos maus tratos e abusos familiares e sociais.

Do grupo de reflexão com as famílias extraímos a síntese de que "as questões graves estão sendo esquecidas", expressão que reflete descrédito nos serviços de saúde educação, nos serviços detransportee nos benefícios, nem sempreacessíveis. Chamamos atenção para o fato de que suas relevâncias convergem para a questão da adequação do seu emprego e trabalho à responsabilidade de cuidar do filho deficiente; à importância de programas sociais que lhes proporcionem transporte adequado paramobilizarem seus filhos em busca de recursos de saúde, a acesso a programas educacionais e laborais; à necessidade de apoio jurídico e social, para quetenham um mínimo dequalidade de vida.

Os gestores relacionaram al guns dentre os principais obstáculos para lidar com o tema direito e violência: a pobreza, a falta de informação, a violência social (confronto tráfico-polícia), o desafio cotidiano de estar transpondo limites junto ao usuário com deficiência e sua família (tendo que avançar na contramão da exclusão e discriminação), a dificuldade de atender à complexa demanda das comunidades (especialmente, o enfrentamento da pobreza) ea restrição orçamentária para financiamento dos projetos e programas.

Também ficou evidente, a partir dos depoimentos dos vários atores, queén ecessário ampliar eadequar programas de combate à pobreza e melhor difundir leis e documentos que instruam sobre direitos das pessoas com deficiência. Fazendo eco às vozes dos familiares, recomendamos a difusão de pólos de assistência social, munidos de informações sobre direitos, visando à divulgação deleis, benefícios e instituições especializadas no atendimento.

Em resumo, será preciso sistematizar estratégias de prevenção, capacitar profissionais e apoiar famílias com dinâmica de violência na área da deficiência e risco social, para que consigam ultrapassar mais esse obstáculo.

\section{Colaboradores}

0 artigo, cujo conteúdo foi proposto e organizado por FG Caval cante, éfruto de análise, elaboração e redação em comum, realizada por ela e por MCS Minayo. 


\section{Agradecimentos}

Aos gestores das instituições integrantes do presenteestudo pelo apoio econfiança, especialmente a Leda de Azevedo e Carlos Alberto da Silva Rocha (FUNLAR), a José Augusto Alves de Britto (IFF), a Moacira Garcia Veranio Silva (CRIART), a Antonio Ivo de Carvalho e Simone Gonçalves de Assis (ENSP/CLAVES), a Tarquínio Prisco Lemos da Silva (Vice-Reitora da UVA). À equipe de pesquisadores Alice M arinho, OIga Bastos, Vanda Valadão, Salete Maimone, Milena de Carvalho, M ichelline Fiaux e Rejane Valdene e aos alunos de iniciação científica Luiza Reis, Isis A brantes, M aurício Ferreira, Sérgio M achado, FelipeFreitas eAlexandre Ávila, agradecemos pela dedicação e generosidade ao longo da presente investigação.

\section{Referências}

1. Cavalcante FG, M arinho ASN, Bastos OM, Deus VV, Maimone MS, Carvalho M M, Fiaux MP, Valdene RSR. Diagnóstico situacional da violência contra crianças e adolescentes com deficiência em três instituições do Rio de Janeiro. Cien Saude Colet 2008; 14(1):45-56.

2. Convenção sobre os direitos da criança. [acessado 2007 ab 20]. Disponível em: http://www.dhnet.org.br/ direitos/sip/onu/textos/tratado11.htm

3. Brasil. Senado Federal. Constituição (1988). Brasília: Centro Gráfico; 1988.

4. Brasil. Câmara dos Deputados. Estatuto da criança e do adolescente. Brasília: Câmara dos Deputados; 2001.

5. Organização das Nações Unidas. Declaração dos Direitos Humanos. Assembléia Geral das N ações Unidas; 1948.

6. Organização das Nações Unidas. Declaração dos Direitos do Deficiente M ental. Assembléia Geral das Nações Unidas; 1971.

7. Organização das Nações U nidas. Declaração dos Direitos das Pessoas Deficientes. Assembléia Geral das Nações Unidas; 1975.

8. Congresso Europeu de Pessoas com Deficiência. Declaração de Madri. Madrid; 2004.

9. Ferreira WB. Aprendendo Sobre os Direitos da Criança e do Adolescente com D eficiência. Guia de orientação a Família, Escola e Comunidade. Suécia: Save the Children; 2003.

10. Cavalcante FG, M arinho ASN, Bastos OM, M aimone MS, Deus VV, Valdene RSR, Carvalho M M, Fiaux MP, Reis LH NL, Abrantes IS, Silva M F, M achado ST, Freitas FF, Ávila AT. Violência e direitos no campo da deficiência: percorrendo os caminhos de uma pesquisa. Relatório técnico, Volume I. Rio de Janeiro: Claves/ Ensp/Fiocruz; 2007.

11. United Nations. Rights of the child. General Assembly, 29 August 2006 (A/61/299):1-34.

12. Pinheiro PS. Violence against children: a global report. Cien Saude Colet 2006; 11(2):453-460.

13. Global Initiative to End All Corporal Punishment of Children. Global Summary of the Legal Status of Corporal Punishment of Children, 28 June; 2006.

14. World Health Organization. Global Estimates of Health Consequences due to Violence against Children. Background paper for the U nited Nations Study on Violence against Children. Geneva: WHO; 2006.

15. UNICEF Innocent Research Centre. Changing a Harmful Social Convention: Female Genital Mutilation/ Cutting. Innocent Digest 2005; 12.

16. International Labour Office. The End of Child Labour: Within Reach. Global Report. Geneva: ILO; 2006.

17. UNICEF/The Body Shop International PIC. Behind Closed Doors: The Impact of Domestic Violence on Children. United Nations Population Division data for global population under 18 years for 2000 and domestic violence from 1987 to 2005. London: UNICEF/The Body Shop International PIc; 2006.

18. Metts R. Disability Issues. Trends and Recommendations for the World Bank. Washington, D.C.: World Bank; 2000.

19. Elwan E. Poverty and disability - a survey of the literature. Washington, D.C.: World Bank; 1999.

20. Wolfensohn JD. Poverty reduction strategies: their importance for disability. Washington, D.C.: Disability and Development Team; 2004. 
21. Goldson E. M altreatment among children with disabilities. Infants and Young children 2001; 13:44-54.

22. AIAS Bologna Onlus, Fenacerci, Disability Now \& Disminuidos Físicos de Aragón. Childhood, Disability $\&$ Violence Project. Empowering disability organizations to develop prevention strategies. Full Report. European Commission: Daphne Programme; 2004.

23. UNICEF. Violence against Disabled Children. Un Secretary Generals Report on Violence against Children Thematic Group on Violence against Disabled Children. Findings and Recommendations. Summary Report. New York: United Nations; 2005.

24. American Academy of Pediatrics, Assessment of $\mathrm{Mal}$ treatment of Children with Disabilities. Pediatrics 2001; 108(2):508-552.

25. Gonzalvo GO. Qué se puede hacer para prevenir la violencia y el maltrato de los niños con discapacidades? An Pediatr (Barc) 2005; 62(2):153-157.

26. Cavalcante FG, Goldson E. Situational analysis of poverty and violence among children and youth with disabilities in the Americas - an agenda proposal. Cien Saude Colet 2008; 14(1):7-20.

27. Guareschi PA, Jacques, M GC, Strey MN, Bernardes M G, Carlos AS, Fonseca TMG, organizadores. Psicologia social contemporânea. Petrópolis: Vozes; 1991.

28. Moscovici S. Prefácio. In: Guarechi P, Jovchelovitch S. Textos em representações sociais. Petrópolis: Vozes; 1994.

29. Jodelet $D$. Les représentations sociales: un domaine en expansion. In: Farr R, M oscovici S, editeurs. Psycologie sociale. Paris: Presses U niversitaires de France; 1989.

30. M inayo MCS. 0 desafio do conhecimento: pesquisa qualitativa em saúde. São Paulo: Hucitec; Rio de Janeiro: Abrasco; 2006.

Artigo apresentado em 03/09/2008

Aprovado em 09/10/2008 